\title{
DINÁMICAS IDENTITARIAS Y POLÍTICAS PÚBLICAS PARA LA TRANSICIÓN HACIA LA AGROECOLOGÍA DE LOS PEQUEÑOS AGRICULTORES DEL CHACO ARGENTINO.
}

Paula C. SERPE ${ }^{1}$

\author{
Valeria A. HERNÁNDEZ ${ }^{2}$
}

\begin{abstract}
Resumen:
Las críticas a la agricultura industrial abrieron el debate sobre las "agriculturas alternativas" para la transición hacia nuevos sistemas sustentables. Una de las respuestas generadas se plasmó en la idea de agroecología. En este artículo analizamos desde un enfoque etnográfico el proceso de construcción de "identidad agroecológica" de un grupo de productores del Departamento Bermejo (provincia de Chaco) y el rol de las políticas públicas en dicho proceso.
\end{abstract}

\section{Abstract:}

Criticism of industrial agriculture opened the debate on "alternative agriculture" for the transition to new sustainable systems. One of the responses to this discussion generated the idea of agroecology. In this paper, we analysed from an ethnographic approach the process of building an agroecological identity within a group of family farmers in the Bermejo Department (Chaco Province) and the role that the public policies play in this transformation.

Key words: agroecology - family farming - public policies - identities - sustainable development

\footnotetext{
${ }^{1}$ Profesora de Enseñanza Media y Superior en Ciencias Antropológicas, UBA.Becaria Doctoral CONICET. Programa de Estudios Rurales y Globalización, IDAES, UNSAM.

Dirección postal: Av. San Martín 1997, 9³4, 1416, CABA.

Correo electrónico: pcserpe@gmail.com

${ }^{2}$ Doctora en Etnología y Antropología Social, Escuela de Altos Estudios en CienciasSociales

(París).Institut de Recherche pour le Développement (IRD, Francia).

Programa de Estudios Rurales y Globalización, UNSAM.

DP: Esmeralda 2043, 1604, Vicente López, Buenos Aires. C.E:valeria.hernandez@ird.fr
}

Fecha de recepción del artículo: Agosto 2020

Fecha de evaluación: Octubre 2020 


\section{Résumé :}

La critique de l'agriculture industrielle a ouvert le débat sur "les agricultures alternatives" permettant une transition vers de nouveaux systèmes durables. L'une des réponses s'est concrétisée dans l'idée d'agroécologie. Sur la base d'une enquête ethnographique nous analysons dans cet article le processus de construction de l'identité agroécologique d'un groupe d'agriculteurs du département Bermejo (province du Chaco) et le rôle des politiques publiques dans ce processus.

Mots clés: agroécologie - agriculture familiale - politiques publiques - identités développement durable

\section{Introducción}

En los años 1990, el reconocimiento a nivel internacional de los límites de la agricultura basada en el modelo de la Revolución Verde (intensificación de la producción mediante el uso de semillas híbridas, agroquímicos, mecanización de labores) abrió el debate sobre las "agriculturas alternativas" (Altieri y Anderson, 1986) y la necesidad de producir conocimiento para sustentar y acompañar la transición hacia nuevos sistemas sustentables. Las agencias multilaterales (FAO, CEPAL, IICA, etc.) y los estados nacionales integraron entonces en sus políticas y programas de desarrollo el apoyo y la promoción de la "transición ecológica" (Tilman, 1999). Una de las respuestas generadas se plasmó en la idea de agroecología, definida tempranamente como la disciplina que produce las bases científicas para una agricultura alternativa (Altieri y Anderson, 1986; Altieri y Toledo, 2010). A partir de allí, el campo de la agroecología comenzó a desarrollarse sobre la base de estudios multidimensionales que incluyeron aspectos agronómicos, sociales y ecológicos. En la actualidad, el campo de la agroecología se propone como una visión integral de lo alimentario, conceptualizado a partir de relaciones sociales, afectivas y simbólicas (Sevilla - Guzmán y Soler Montiel, 2009; Gudynas, 2011; Hernández et al., 2014; Giraldo y Rosset, 2016). En la Argentina, desde los años 2000, este campo es acompañado por políticas públicas tanto de nivel nacional como provincial, así como por asociaciones y organizaciones de productores agroecológicos con presencia en diferentes provincias del país (Sarandón y Flores, 2014; Sabourin et al., 2017).

En este artículo, nos proponemos dar cuenta del proceso de construcción de la identidad agroecológica que llevaron adelante productores que se reconocen "en transición hacia la agroecología" en el Departamento Bermejo (provincia de Chaco) y el rol de las políticas públicas en ese proceso. Dicho departamento se ubica al este de la provincia de Chaco, en la frontera con Paraguay, cuenta con 24.329 habitantes (censo 2010) y está integrado por seis localidades -Puerto Eva Perón, Puerto Bermejo, Isla del Cerrito, General Vedia, Las Palmas y La Leonesa- las cuales tienen su casco urbano, rodeado por parajes. 


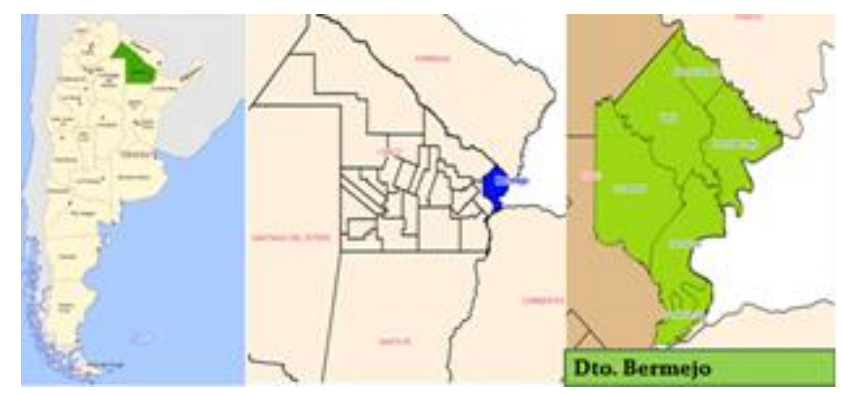

Figura 1

Allí realizamos un estudio antropológico que adoptó una metodología que combinó la etnografía (2016 a 2017), técnicas de tipo cuantitativas (relevamiento del uso y la tenencia de la tierra) y cualitativas ( 7 talleres participativos entre 2016 y 2019; relevamiento de artículos de prensa; trabajo sobre material fotográfico de la zona), revisión de fuentes secundarias (fundamentalmente, convenciones internacionales sobre la cuestión del desarrollo y sus consecuencias, políticas públicas nacionales y provinciales enfocadas en el sector agropecuario y en la agroecología). Con residencia en Las Palmas, nos fuimos desplazando al resto del Departamento según las lógicas propias que se fueron dando a partir de nuestro diálogo con los actores de la producción agropecuaria local. Se trató de una etnografía colectiva ${ }^{3}$ (Hernández, 2019) concebida como una práctica de frecuentación de un campo social de manera compartida por un grupo de antropólogos, la creación de un registro único del material etnográfico que integra el material generado por cada investigador y la realización de sesiones colectivas para el trabajo interpretativo (tanto durante el trabajo de campo como luego, sobre el material etnográfico resultante). Con el objetivo de profundizar la reflexión sobre el campo agroecológico a nivel nacional y poner así en contexto las observaciones realizadas en Bermejo, hicimos una etnografía de tipo multisituada (Marcus, 2001) en 2018 para integrar al análisis la lógica de las redes en agroecología.

A la vez, dado que el último Censo Agropecuario Nacional que se realizó correctamente en la Argentina fue en 2002, fue necesario hacer un relevamiento in situ por nuestros propios medios para captar la configuración productiva de Bermejo. En este sentido, llevamos adelante en 2016 un "barrido territorial", una técnica que utilizamos en estudios anteriores en zonas rurales de Argentina (Hernández et al, 2009 y 2013). Seleccionamos un área a relevar de 90.000 ha entre Las Palmas y La Leonesa, dos localidades de Bermejo que conforman una unidad socio-histórica según pudimos comprender durante el trabajo de campo y la bibliografía consultada (Fueyo Sánchez, 2014). Luego, entrevistamos habitantes de referencias de dicha área con un ejemplar del mapa de catastro para ir identificando los usos y tenencias de cada parcela. Aquí, utilizaremos información sobre las superficies en producción (77706,5 ha) que pudimos consistir (75708,5 ha).

A los fines de desarrollar el análisis propuesto, primero, restituiremos el contexto histórico en el que toma forma la agroecología en Argentina en relación a los debates

\footnotetext{
${ }^{3}$ El equipo de antropólogos se organizó para asegurar una presencia continua a lo largo de 2016 y 2017 , mientras que en 2018 se pasó a una modalidad de presencia intermitente, con frecuencia mensual, por un periodo de 7/10 días. Se produjo así un corpus de material etnográfico compuesto de 108 entrevistas individuales con productores agropecuarios, 30 entrevistas con agentes de desarrollo rural y decidores políticos, 477 registros etnográficos y 7 talleres participativos cuya temática y actividades fueron definidas en conjunto con los interlocutores locales.
} 
sobre las "vías del desarrollo" y cuáles fueron las declinaciones particulares que estos procesos tuvieron en Bermejo. Subrayaremos el rol de las políticas públicas en el proceso de transición hacia la agroecología que conocen los productores familiares de Bermejo. Luego, analizaremos tres iniciativas que dan cuenta del proceso de institucionalización de la agroecología en Bermejo ${ }^{4}$. Por último, concluiremos con algunas reflexiones que retoman los debates internacionales para confrontarlos con las dinámicas territoriales que pudimos estudiar en el chaco argentino.

\section{EI debate en torno de las "vías del desarrollo" en América Latina y en Argentina con foco en el sector agropecuario.}

\section{I.a. El desarrollo en la periferia}

En América Latina, se introdujo con fuerza la cuestión del desarrollo a partir de la década de 1960 con la creación de la Alianza para el Progreso, un programa a 10 años financiado por organismos multilaterales de crédito (principalmente el Banco Interamericano de Desarrollo, BID), con el objetivo explícito de "mejorar" la vida de los habitantes latinoamericanos (Manzanal, 2017). En este contexto, la Argentina impulsó el ideario desarrollista con foco en la actividad agropecuaria a través de políticas de apoyo y promoción de la modernización de los principales sistemas productivos, los cereales y la ganadería. Esto supuso la adopción del paquete tecnológico de la Revolución Verde y el desarrollo de nuevas identidades al interior del mundo agro-rural: el productor como empresario puso la tierra a disposición de un sistema productivo basado en tecnologías de punta (semillas híbridas, maquinización de las labores, agroquímicos) y una gestión profesional de los factores de producción (Gras y Hernández, 2016a).

La década del 1990 fue escenario de una apertura y redefinición del Estado que implicó la desregulación y reforma del sector público agrícola, así como la promoción de una agricultura intensiva en capital que no todos los estratos de productores estaban en condiciones de desarrollar (Murmis, 1998). En esta etapa también se dio la comercialización del primer cultivo transgénico, la soja transgénica resistente al glifosato, utilizada en forma de cuasi-monocultivo, sembrada con las más modernas maquinarias de siembra directa, en un sistema de gestión empresarial que se inscribe en el paradigma del agronegocio (Hernández, 2007; Gras y Hernández, 2016a). La innovación tecnológica trajo aparejada una importante reducción en la demanda de mano de obra, complicando la subsistencia de gran parte de las poblaciones rurales que dependían de ella. Así, la presión por la capitalización y la tecnificación provocaron el desplazamiento de la agricultura familiar y campesina por nuevos actores empresariales, mientras que otros debieron transformar sus estrategias de acumulación para seguir siendo parte del sistema, como los grandes propietarios (terratenientes). Hacia mediados de los 2000, el Agronegocio se había posicionado como un modelo hegemónico, orientando el desarrollo del sector agropecuario a nivel nacional; el modelo de agronegocios (MA) implicó la introducción de formas empresariales complejas relacionadas con la dinámica financiera internacional y el control directo de los recursos agrícolas y no agrícolas (políticas públicas, tecnologías, infraestructura, etc.) (Gras y Hernández, 2016b).

En contrapartida, quienes formaban parte de la pequeña producción familiar campesina o eran trabajadores rurales dependientes se constituyeron en los "nuevos pobres rurales" (Gras y Hernández, 2008; Murmis, 1998): muchos migraron hacia otras zonas del país,

\footnotetext{
${ }^{4}$ Los nombres de individuos e iniciativas aquí referidos han sido rebautizados siguiendo los lineamientos éticos del trabajo de campo informado de confidencialidad y anonimato (Restrepo, 2016).
} 
principalmente las periferias de las ciudades, engrosando los barrios más vulnerables; otros, en cambio, permanecieron en el campo sin poder capitalizarse. De este modo, los procesos de tecnificación y capitalización significaron que estas poblaciones queden en una situación de población sobrante, ya que dejaban de cumplir una función en términos de su utilidad para el capital (Li, 2010). Para estos últimos, se llevaron adelante políticas focalizadas para reactivar la producción para el autoconsumo y promover el asociativismo como vía para superar los problemas de escala, de incorporación de tecnología y mejorar la administración (Murmis, 1998; Soverna, 2016).

\section{El ajuste estructural en Bermejo.}

En el Departamento Bermejo, estos procesos tuvieron impactos particulares de acuerdo a su configuración histórica, económica y social. Desde fines del siglo XIX hasta fines del XX, estuvo hegemonizado por el Ingenio azucarero Las Palmas del Chaco Austral. Fue un gran complejo agroindustrial que llegó a ocupar una concesión de cien mil hectáreas de superficie para el cultivo de caña azúcar de las 265.200 ha que tiene el Departamento Bermejo, es decir, casi un $40 \%$ de la superficie total del Departamento. En 1969, fue intervenido por el Estado Nacional con el fin de reorganizar su funcionamiento y evitar así su cierre definitivo en el marco de una crisis internacional del precio del azúcar. Bajo la órbita del Ministerio de Bienestar Social (Leyes 18172 y 18173 del 7 de abril de 1969), el Ingenio redujo la superficie ocupada a 60.000 has.

Mientras operó, fue la fuente principal de empleo de la zona, en sus oficinas administrativas, en sus fábricas, en los cañaverales y obrajes. A su vez, garantizaba el acceso a la tierra y la vivienda a gran parte de la población del departamento, compuesta mayoritariamente de indígenas qom y criollos provenientes de Paraguay o de la provincia de Corrientes (Ferrau, 2003; Schaller, 1986). La lógica productiva del Ingenio distribuyó roles entre los espacios y los pobladores: en la localidad de Las Palmas, se instalaron las oficinas administrativas y las plantas industriales, mientras que en el resto de las localidades y parajes se asentaron la mano de obra del complejo (macheteros ${ }^{5}$ para la caña, pequeños productores de algodón y peones que se encargaban del ganado) y los pequeños comerciantes.

Sin haber logrado su plena reactivación, en el año 1991, en el marco de las políticas de desregulación y privatización, el Ingenio fue vendido y luego, en 1992, sus tierras e instalaciones fueron dispuesta en remate público por el decreto nacional $n^{\circ} 1274 / 92$. En este proceso se concedió la posibilidad de comprar tierras con planes de pagos en cuotas a 10 años. Quienes alquilaban tierras al ingenio, tuvieron prioridad en la compra. En general, fueron productores de arroz y de ganado vacuno.

La memoria social que registramos durante el trabajo de campo pone en escena el contraste entre una época "de oro", dominada por el progreso, la modernización y el pleno empleo, en contraposición a un presente de estancamiento económico, dificultad para encontrar empleo y amenazas representadas por dos grandes figuras: el agronegocio y el narcotráfico. Una y otra vez, los actuales pobladores relatan el proceso de desarrollo, apogeo y caída del "imperio" azucarero de los Hardy - los hermanos irlandeses que lo fundaron -, cuya grandeza aún se puede vislumbrar en los escombros de las múltiples construcciones por ellos levantadas en cada rincón del pueblo. Las Palmas convirtió los restos del "imperio" en emblemas de su identidad: a la entrada del pueblo, se exhiben

\footnotetext{
${ }^{5}$ Localmente, se denomina de esta forma a quienes trabajaban de cortar caña. En otras partes del país, a quienes llevan adelante este tipo de actividad se los conoce como zafreros.
} 
como piezas de museo la locomotora que recorría los parajes para levantar la cosecha y una copia del gigantesco dinamo que los Hardy instalaron para dar electricidad a su planta de procesamiento y que benefició con una red de luz para el casco urbano.

“...el Ingenio tenía una influencia casi en todo el Departamento Bermejo, e inclusive hacia General San Martín. Había chacras que estaban bastante alejadas de acá, en dirección a Gral. San Martín, de donde se traía la caña de azúcar, en tren. Tenía un ferrocarril propio de trocha angosta, donde traían la caña de azúcar y después llevaban mercadería. Bueno, todo ese sistema de producción, esa organización administrativa, creó un modelo distinto a otros. Entonces, eso se nota hasta hoy en día, en la gente, en la organización de la sociedad, (...) También trajo población de otros lugares" (Entrevista a productor ganadero, feedlot mayo 2016)

Cuando la narración avanza hasta llegar al tiempo presente, hay un actor que aparece como el "heredero" del rol asumido por el Ingenio en tanto motor económico del Departamento Bermejo: se trata del principal empresario del agronegocio, al que llamaremos Bernardo. Si bien la actividad que mayor número de hectáreas ocupa en la zona es la cría extensiva de ganado bovino, la producción rizícola y piscícola que lleva adelante Bernardo es la más relevante en términos sociales (por el lugar simbólico que hemos señalado), económico (por los empleos generados por el sector privado local) y políticos (por las alianzas logradas a nivel municipal, provincial y nacional) ${ }^{6}$. En las entrevistas de trayectoria productiva, Bernardo aparece como un referente principal del paisaje local, tal como expresa uno de los ganaderos de Bermejo en este pasaje de su trayectoria:

"Y acá en nuestra zona está dominado por un productor, Bernardo, él siembra 3600, más o menos, hectáreas de arroz; que está haciendo todo un emprendimiento, unos molinos...(...) Y ahora está con este tema nuevo: el Pacú (...) Fue tan interesante el proyecto, y dio con personas que lo dirigieron muy bien a todo eso, y se convirtió en esto que es un emprendimiento, que está visto a nivel de país, como uno de los más grandes. Piscicultura de agua dulce." (entrevista, mayo 2016)

Por su parte, quienes no contaban con el capital necesario para comprar tierras se vieron en la necesidad de llevar adelante diversas estrategias para permanecer en sus territorios. Hasta el cierre el complejo todos eran trabajadores que se organizaban como tales en el Sindicato Único de Trabajadores de Las Palmas. Los procesos de disputa de tierra activaron una diferencia hacia el interior entre indígenas y criollos. Si bien eran reconocidas las distintas ascendencias, no operaron de ese modo hasta ese evento en particular. Fue fundamental la proclamación de determinadas normativas, como la reforma constitucional de 1994, que en en el artículo 75 inciso 17 reconoce la preexistencia de los pueblos originarios y el derecho a la propiedad comunitaria. En ese marco, las comunidades indígenas Qom se asesoraron con una ONG (INCUPO) para acceder a títulos comunitarios (4048 ha).

En cambio, los criollos se organizaron en la Unión de Pequeños Productores Chaqueños (UnPeProCH), logrando permisos de ocupación de la provincia de 7 ha entregados a familias miembros de la organización en torno a las que se formaron asentamientos. No fueron pocas las familias que quedaron por fuera de estos acuerdos. Muchas de ellas buscan adquirir la propiedad a través de ley conocida como "veinteañal" o derecho de usucapión, apelando a la posesión de la tierra por más de 20 años y a la falta de pago de la totalidad de las cuotas por parte de aquellos con quienes están en disputa. Algunas hasta

\footnotetext{
${ }^{6}$ Existe otro productor arrocero en Bermejo, pero no tiene las funciones sociales, económicas y políticas que acabamos de evocar para Bernardo.
} 
el día de hoy están en conflicto con "propietarios" que pagaron solamente la primera cuota del plan de pago mencionado previamente. Otros acceden a la tierra a través de acuerdos informales con privados donde se les ofrecen unas hectáreas de tierra a cambio de trabajo no pago, como el mantenimiento de los alambrados de una gran estancia, por ejemplo.

Así se produjo una diferenciación que devino en tensiones hacia el interior del sector de la agricultura familiar que perduraron, entre quienes títulos comunitarios, los que tienen permisos de ocupación y los que están en conflicto o sólo tiene acuerdos de palabra. En una entrevista a un pequeño productor criollo que está involucrado en un conflicto judicial por tierras se relata el modo en que las relaciones sociales en el paraje se vieron afectadas luego de que los pobladores indígenas titularizaron sus tierras:

"D: digamos, la gente en sí también es muy quedada en la comunidad, digamos. No es, digamos, que tira uno va, el otro se queda, así, no. Como que no le interesa mucho, digamos (...) y acá también está un poco dividida, porque están por un lado los aborígenes, ellos ya tienen su tierra, ellos están tranquilos. Ellos tienen su tierra (...) y, por ejemplo, nosotros les decimos "vamos a meter a pelear nuestra tierra" y ellos dicen "para qué nos vamos a meter a pelear nosotros, si nosotros ya tenemos nuestra tierra". Y ahí siempre hay un tire y un afloje. Y por ahí está un poco complicado. No tenemos problema con ellos, pero esa es la realidad, pero ellos ya tienen y nosotros no tenemos" (octubre 2016)

Estas normativas se pueden interpretar en términos dispositivos de "gubernamentalidad" para la administración de una población, es decir, personas, individuos, colectividades. Es decir, las políticas construyen nuevas subjetividades. Siempre están categorizando diferentes grupos de personas, asignándole identidades y construyéndolas activamente (Foucault, 1999; Shore, 2010). En este marco, luego del cierre del ingenio, los otrora trabajadores del ingenio fueron objetivo de un doble desplazamiento: por un lado, de trabajadores a "pobres rurales beneficiarios" de políticas focalizadas; por otro, la división entre indígenas y criollos.

\section{I.b. Programas de desarrollo social para el noreste argentino.}

En el contexto de la desregulación del sector público agrícola argentino, se ejecutaron programas de desarrollo rural destinados a aquellos productores que no reunían las condiciones para convertirse en empresarios con financiamiento del Fondo Internacional de Desarrollo Agrícola (FIDA). El criterio para definir el perfil de los destinatarios de este tipo de programas incluía indicadores de pobreza, residencia en zonas rurales y vinculación con la actividad agropecuaria y forestal (Lattuada et al., 2015; Soverna, 2016). Entre ellos, se destacó el "Programa de Crédito y Apoyo Técnico para Pequeños Productores del Noreste Argentino" (PRODERNEA), en vigor entre 1991-1996, que consistió en otorgar créditos para la promoción y la capacitación de organizaciones de pequeños productores de Misiones, Corrientes, Chaco y Formosa. El PRODERNEA otorgaba el marco para el desarrollo de proyectos destinados a paliar las situaciones de pobreza rural, mientras se contribuía "a la conservación a largo plazo del medio ambiente, a partir del manejo de los recursos naturales renovables"7.

Este tipo de programa fueron implementados a través de técnicos o extensionistas rurales, principalmente, de organizaciones no gubernamentales con presencia en las provincias del norte argentino (Castilla, 2017), estableciendo una dinámica de intervención que perdura hasta la actualidad: el trabajo en grupos acotados asesorados por personal técnico. Como en Bermejo, donde la ONG INCUPO trabajó en el marco del PRODERNEA con

\footnotetext{
${ }^{7}$ https://www.ucar.gob.ar/index.php/prodernea
} 
mujeres indígenas para la elaboración de productos con valor agregado. En una charla con Sofía, una mujer qom de unos 60 años, ella nos comentaba su experiencia en las capacitaciones promovidas por la ONG:

"Y después cuando hay encuentros lejos ya nos lleva a nosotros. Pero nosotros estamos trabajando a cada rato. Vamos con Don Eduardo [de la ONG INCUPO]. Está la capacitación de frutales del monte, de hacer dulce de toda clase de fruta, pero del monte.

Viajé a muchos lugares. Sí, así, pero yo siempre me iba sola, sin mis hijos, ni nada. Pero con las otras mujeres de Pampa del Indio, de otros lados. Y después [fuimos a] Formosa, Estanislao del Campo, Asunción, Paraguarí al fondo. Conocí todas partes. En Córdoba. Acá en Santa Fe. (...) muy lindo para aprender muchas cosas." (marzo 2019)

Luego de este relato, buscó algunas fotos que conservaba de estos viajes, donde aparecía con otras mujeres qom y con Don Eduardo, rodeada de los dulces elaborados durante la capacitación. También nos habló de la capacitación para hacer queso y nos mostró la prensadora que instaló en su casa luego de ese otro viaje. En estas experiencias, Sofía nos mostraba una identidad construida en base a elementos novedosos: ya no como madre, responsable de hogar y ligada al territorio, sino como una mujer viajante, en un escenario social y productivo.

Además, a nivel nacional se creó en 1992 el programa ProHuerta, caracterizado como un programa de nutrición y alimentación para la población con Necesidades Básicas Insatisfechas (NBI), cuyo objetivo fue promover la "seguridad alimentaria". La institución encargada de ejecutarlo fue el Instituto Nacional de Tecnología Agropecuaria $(\text { INTA })^{8}$, mientras que el financiamiento fue gestionado por Desarrollo Social. Como señala Ivancovich (2015) 'resultó ser una 'novedad' al interior del INTA, ya que su tradicional perfil 'productivista' debió ceder lugar a la propuesta 'social' que propone el ProHuerta para promover el autoconsumo mediante la entrega de semillas y capacitaciones tanto para producción de huerta, agregado de valor y comercialización." $(: 25)$.

"Al comienzo comía la gente arroz hervido, esa era la comida del día, no se veía nada de verdura (...) Y en un momento cuando empezamos digamos que había, pero pobre la huerta y después se incrementó con la ProHuerta que aumentó un montón (...) El tema de Pro huerta es algo que funcionó bastante bien, pero viste que eso es, digamos, para capacitar un poco a la gente, orientarla un poco" (Omar, Entrevista, mayo 2017)

Privados de acceso al dinero (empleo en el Ingenio) y viendo fragilizado el acceso a la tierra, los pequeños productores familiares de Bermejo se apoyaron en la experiencia productiva acumulada durante los años de macheteros para desarrollar sus huertas en los asentamientos y lograr, en algunos casos, excedente a ser comercializado en el mercado local. El programa ProHuerta tuvo un rol clave en el impulso de estas huertas, ya que garantizó la provisión de semillas y la capacitación de los zafreros para adoptar las prácticas en tanto "pequeños productores". Fue una política pública central en la construcción de nuevos sentidos sobre los modos de existencia y la práctica agroalimentaria; ella acompañó el pasaje desde una identidad erigida en relación al trabajo para el Ingenio a una nueva asentada en la producción sustentable de alimentos. Una de las herramientas del programa para lograr la formación del nuevo perfil socioproductivo fue la figura de los "promotores voluntarios" quienes tenían por misión involucrar a miembros de las poblaciones locales como "agentes multiplicadores" del ProHuerta (Ivancovich, 2015). La red de "promotores" de Bermejo acompañó a sus vecinos en la producción hortícola y avícola, así como en la comercialización de los

\footnotetext{
${ }^{8}$ INTA dispone de autarquía administrativa y financiera para manejar sus recursos
} 
excedentes, logrando presencia en todo el departamento y con actividad hasta la actualidad. El ProHuerta también proveyó los técnicos que aseguraron un acompañamiento cotidiano, generando un vínculo fuerte con los productores familiares, tal como relató en su trayectoria de vida una productora hortícola:

"Y ahí le comentó el tema de si quería hacer un curso de promotor voluntario del ProHuerta.

(...) Y de ahí charlas y participaciones con el ProHuerta le gustó (...) Entonces, la capacitación esta era para capacitarle a todos los vecinos, y todas esas cosas. (...) Y concientizó bastante todos los vecinos con su huertita, y todos tenían para revender y todas esas cosas." (Entrevista 2016)

La trayectoria de vida del promotor que se menciona en el fragmento citado, al que llamaremos Augusto, da cuenta del modo en que se fue (y se sigue) construyendo el sector de los pequeños productores en Bermejo. Él trabajó con su familia para el Ingenio desde los 7 años y tenía 18 cuando el mismo fue rematado. Aunque ya contaba con producción de huerta y chacra, la venta de frutas y verduras no fue su primera opción, sino que antes probó otras iniciativas, como la venta de pan casero en panaderías de la zona o el corte de leña en un obraje. Debido a la sobreoferta de mano de obra que había en aquel entonces, el salario que obtenía era insuficiente. En el marco de su incorporación al programa de promotores voluntarios en 1994, empezó a vender su producción en verdulerías del pueblo. Luego de unos años, un frutero conocido le sugirió que pase a comercializar en la calle, de forma directa a los consumidores, para conseguir mayor margen de ganancia.

"Y bueno ahí fuimos, fue difícil primero, primeramente, por el tema de que era vergonzoso.

No conocer la gente digamos, no saber..., tener ese miedo de hablarle, ofertar, uno, dos por

ahí, y me iba a la otra cuadra y hacía otra oferta. Y por ahí me llamaban, cuando veían la

mercadería buena te llaman viste." (Entrevista, mayo 2016)

La apelación a la "vergüenza" es constante en los intercambios que tuvimos con productores. Aunque la producción familiar de huertas y chacras está muy extendida en el departamento, pocos se animan a vender cara a cara. El sentimiento de vergüenza aparece vinculado al desconocimiento del oficio de la venta, desde cómo seleccionar las verduras con aspecto más "presentable", hasta el modo de abordar los posibles clientes. Augusto es parte de una generación que fue formada para el trabajo asalariado y cuya relación con la práctica agro-productiva se inscribía en un horizonte de sentido preciso: el de procurarse el alimento (autoconsumo). Cuando le pedimos que nos cuente cómo fue el proceso de "vender sus productos", resalta que aprendió "en la calle, de la gente", no de sus padres, ni de sus pares.

En la práctica, este tipo de programas fueron el vector para que llegasen a los territorios rurales "técnicos o extensionistas rurales" cuyo rol fue "ejecutar" los "proyectos de desarrollo rural" para "asistir" a los sectores que no tenían posibilidades de garantizar su subsistencia en el contexto de las políticas neoliberales de ajuste estructural del Estado (Cowan Ros, 2013). En suma, por un lado, las políticas públicas asociaron la figura del pequeño productor y la del pobre rural; por el otro, fueron el vector para el desarrollo de una institucionalidad de promoción social que incidirá en las estrategias de reproducción social de estos sectores, reconfigurando las formas en que se vincularán con el resto de la sociedad y con el Estado. Ambas dinámicas resultan fundamentales para entender la configuración productiva e identitaria que encontramos en nuestro trabajo de campo en el Departamento Bermejo.

\section{I.c. Devenir productor familiar}


A pesar de la gran diversidad de proyectos que se desplegaron en los años 1990, éstos no lograron contrarrestar las consecuencias de las políticas instrumentadas, lo cual se vio reflejado en la disminución de explotaciones agropecuarias: entre 1988 y 2002 el número de unidades productivas pasó de 421 mil a 331 mil, implicando una disminución total de alrededor de 88 mil explotaciones, que en términos relativos alcanza al 21\% (Gras y Hernández, 2008). Luego del default económico del 2001, la mitad de la población argentina quedó por debajo de la línea de pobreza, al tiempo que la polarización entre los más pobres y los más ricos se acrecentó (Beccaria et al 2005).

En este contexto, movimientos y organizaciones sociales comenzaron a llevar adelante experiencias de gestión colectiva del trabajo - como cooperativas de trabajo -, a la vez que se fueron implementando políticas que promovieron formas asociativas de trabajo (Señorans, 2017). El nuevo gobierno (2003), alineado con políticas progresistas, adhirió a las corrientes del post-consenso de Washington, en particular promoviendo la idea de Desarrollo Territorial Rural (DTR) que impulsó la participación de la población rural no sólo en la ejecución de los proyectos, sino también para su definición (Lattuada, 2014). Así, se creó el Programa Federal de Apoyo al Desarrollo Rural Sustentable (PROFEDER) para articular programas que el Instituto Nacional de Tecnología Agropecuaria (INTA) venía motorizando de forma fragmentada (Gisclard et al., 2015).

A su vez, con la creación en el MERCOSUR de la Reunión Especializada sobre Agricultura Familiar (REAF) en 2004, se empezó a fomentar el concepto de agricultura familiar (AF) como forma de concebir a las poblaciones beneficiarias de estos programas. La participación de las organizaciones sociales y políticas de este segmento de la producción y su reconocimiento por parte del Estado cristalizó esta figura como un actor central de las políticas públicas dedicadas al sector. En esta categoría se contiene a una gran diversidad de situaciones: desde colonos o farmers empobrecidos integrados al mercado y tecnificados, hasta campesinos con una mínima comercialización de excedentes (Schiavoni, 2010). De este modo, se dejaba atrás su caracterización en tanto "población rural pobre" y se la impulsaba a asumir un rol económico y productivo en actividades agropecuarias, forestales y pesqueras (Craviotti, 2014; Gisclard et al., 2015; Schiavoni, 2010; Soverna et al., 2008). En adelante, la AF será considerada como un agente fundamental para lograr el objetivo de seguridad alimentaria, con cuidado del medio ambiente. En esta etapa, el ProHuerta pasaría a adoptar de forma explícita a la agroecología como marca distintiva e impulsaría más, fuertemente, la comercialización de los productos de las huertas familiares para superar el autoconsumo (Gisclard et al., 2015) ${ }^{9}$. En 2014 culmina el período de transición en materia de políticas de desarrollo rural (Soverna 2016), cuyos principales resultados fueron la creación de la Secretaría de Agricultura Familiar, jerarquizando así este sector dentro de la estructura del Ministerio de Agricultura, Ganadería, Pesca y Alimentos (MINAGRI), y la sanción de la ley de Reparación Histórica de la Agricultura Familiar, donde se prioriza "las prácticas agroecológicas" (art. 21) como fundamentales para la conservación y el mejoramiento de los suelos y de los recursos naturales.

En este contexto nacional, las provincias también transitaron el proceso de cambio desde una mirada sobre los pequeños productores como población pobre y foco de planes de asistencia social, hacia otra que los posicionaba como actores para garantizar la "seguridad alimentaria" y activar una economía local. En la provincia de Chaco se aprobó

${ }^{9}$ http://prohuerta.inta.gob.ar/acerca-de/ 
en 2010 la Ley provincial 6.547 que creó el Régimen de Consorcios Productivos de Servicios Rurales (CPSR) definidos como "entidades de bien público de servicios a la comunidad" con el objetivo de fortalecer a los pequeños productores y garantizar la promoción de "modelos productivos sustentables para la agricultura familiar". En Bermejo, se formaron cuatro CPSR en 2010 y uno más en 2018, reuniendo en total a más de 500 pequeños productores. Cada uno obtuvo un tractor a usarse de forma comunitaria y depósitos mensuales para cubrir, en parte, los gastos de combustible y reparación. También se entregan semillas.

Este reconocimiento de la $\mathrm{AF}$ será un antecedente fundamental en el proceso de institucionalización de la agroecología que registramos en el trabajo de campo, tal como lo evocaron los propios protagonistas. Otro hito fue la promulgación en 2013 de la ley provincial 7303 de Agricultura familiar y la creación del Instituto de Desarrollo Rural y Agricultura Familiar (IDRAF) como entidad autárquica y dependencia funcional del Ministerio de la Producción de la provincia. Estas medidas consolidaron la AF y la agroecología como su sistema de producción faro, lo cual comenzó a visibilizar la situación de tensión (o incluso enfrentamiento) con el modelo de agronegocios (MA) dominante en la Argentina y en la provincia de Chaco. Los movimientos campesinos y las organizaciones de la AF se involucraron en la arena política-estatal, tanto a nivel nacional como provincial, promoviendo el enfoque agroecológico como un modo de generar sistemas productivos en sintonía con las tecnologías y saberes a su alcance y en línea con su visión política de la actividad agrícola (Sarandón y Flores, 2014; Souza Casadinho, 2014; Vía Campesina, 2015).

\section{La identidad "en transición a la agroecología": procesos de subjetivación y rol del estado}

Hoy en día, el Departamento Bermejo se caracteriza por una gran diversidad de perfiles productivos: la actividad que mayores extensiones ocupa es la cría extensiva de ganado bovino. Le sigue la producción de arroz, donde se registró la presencia de únicamente dos productores muy capitalizados, al punto de llegar a controlar casi la totalidad de la cadena de valor. Por último, encontramos pequeños productores diversificados, que combinan frutihorticultura con producción animal (aves, porcinos, ganado menor y mayor).

Luego de procesada la información del barrido territorial, identificamos 275 unidades productivas, de las cuales el 66\% (181) corresponde a pequeños productores, generalmente ubicados en lotes compartidos por varias familias: 


\section{Tipo de explotaciones agropecuarias de Bermejo}

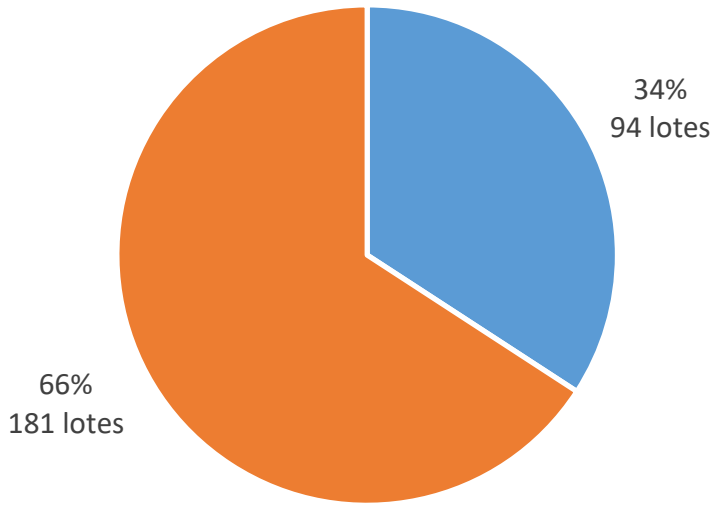

- Con Limites Definidos

- Sin Limites Definidos

Figura 2

\section{Distribución de superficies}

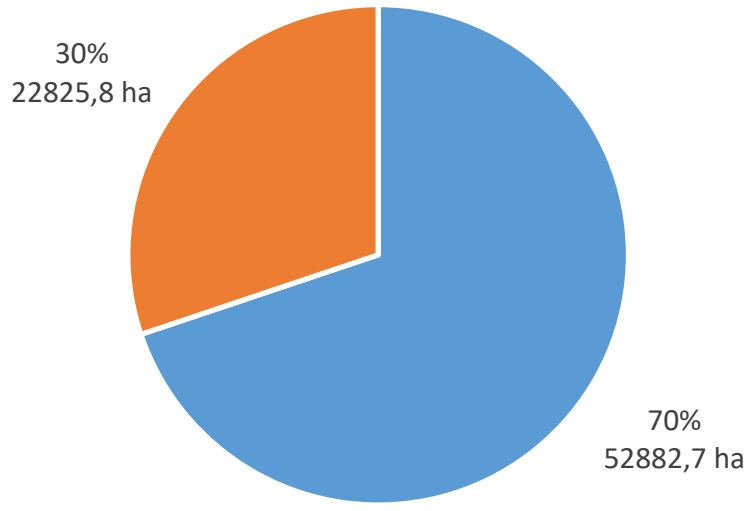

- Con Limites Definidos

- Sin Limites Definidos

\section{Figura 3}

Fuente: Barrido territorial 2016

Las explotaciones de los pequeños productores son aquellas caracterizadas como "sin límites definidos", ya que se encuentran en lotes catastrales donde conviven varios hogares ${ }^{10}$. Estas parcelas tienen los distintos tipos de situaciones de tenencia que mencionamos previamente (sección I.a.).

En medio de un escenario complejo, donde distintos tipos de tenencia de tierra se entrelazan, se desarrollan las unidades de la AF con estrategias de diversificación productiva. En chacras de 2,5 ha de extensión en promedio, se emplazan los principales

\footnotetext{
${ }^{10}$ En general, una explotación se corresponde con un hogar. Usamos de referencia el concepto de hogar censal particular en los términos definidos por el Instituto Nacional de Estadística y Censos de la Argentina: "Grupo de personas, parientes o no, que viven bajo un mismo techo de acuerdo con un régimen familiar, es decir, comparten sus gastos de alimentación. Las personas que viven solas constituyen cada una un hogar." https://www.indec.gob.ar/textos_glosario.asp?id=14
} 
cultivos de verano: maíz, poroto, zapallo, batata, sandía, melón y mandioca. A estos, se suman huertas (media hectárea en promedio) dedicadas a cultivos de ciclos más cortos, que intentan sostener durante todo el año, aunque son más propicios para el invierno como "el verdeo" (lechuga, achicoria, rúcula, perejil), cebolla y ajo. Además, habitualmente tienen árboles frutales (mamón o cítricos) y producción animal (avícola, porcina y bovina) de donde obtienen productos para venta y consumo familiar (huevos y leche para la elaboración de quesos). La comercialización se realiza de forma directa -a través de un puesto que atienden en ferias de proximidad o a clientes particulares y vecinos- o indirecta -a verdulerías de los pueblos cabecera. En algunos casos, la producción primaria se complementa con algunos productos elaborados, como dulce, cestería, licores. También, suelen realizar trabajo extra predial desarrollado en condiciones de informalidad (albañilería, ladrillería, producción de carbón, artesanías). Además, este sector recibe subsidios estatales a los que tienen derecho por tratarse de poblaciones consideradas vulnerables. Uno de los ejemplos más extendidos es la asignación universal por hijo, un plan social que existe en Argentina desde 2009 y que se otorga a menores de edad cuyos padres o madres no perciben ningún ingreso formal.

De este conjunto, alrededor del $17 \%$ se autodefine como "productor en transición a la agroecología". En un principio, la noción de transición la tomamos de uno de los primeros intercambios que tuvimos con una técnica del INTA que trabaja en la zona hace más de 10 años: 'son 'productores en transición agroecológica'. Por ejemplo, la Feria Franca va con las banderas de la agroecología y la manejan lo mejor que puede. No es súper pura [la práctica agroecológica que realizan]." (Registro de campo, mayo 2016). Al desarrollar el concepto, la técnica explicó que frente al peligro de las hormigas si los productores ven amenazada la producción (no sólo para la venta sino también para el autoconsumo familiar), "le tiran un hormiguicida y listo. No le tiran glifosato. Es un proceso que es lento, que lo están transitando." (Registro, mayo 2016).

Si bien en este intercambio, el énfasis está puesto en la dimensión técnica, a través del trabajo de campo pudimos comprender que se trata de un proceso que involucra dinámicas identitarias, políticas y económicas, las cuales se despliegan en escalas locales y globales. Identificamos que la mayor parte del conjunto de productores "en transición hacia la agroecología" pertenece a familias que estuvieron en posición de dependencia del Ingenio: macheteros, empleados, capataces, peones, etc. Cuando consultamos a los productores, nos comentaron que el Ingenio fomentaba que los macheteros tuviesen su propia producción para garantizar la alimentación familiar, ahorrándose, de este modo, los costos de la reproducción de la mano de obra en los períodos de interzafra (Gordillo, 1995; Meillassoux, 1977). Esas huertas y chacras domésticas, que generalmente estaba a cargo de las madres del hogar, una vez que el complejo azucarero cerró sus puertas, pasaron a constituirse en fuentes de ingresos, en procesos en los que se involucraron organizaciones sociales, ONG y agencias estatales.

A su vez, para un pequeño productor familiar, ser promotor de ProHuerta o beneficiario de programas de desarrollo rural (como el PRODERNEA) no sólo permite el acceso a preciados insumos (semillas, gallinas, equipos) y capacitaciones para la producción, sino que también habilita a circular por espacios organizados por fuera de su lugar de residencia, ampliando su horizonte social y material. Tal como registramos en las entrevistas de vida y en los talleres que organizamos en Bermejo con estos actores locales, su participación en actividades de promoción de la agroecología es la oportunidad de vivir 
otras experiencias y empaparse de los debates que se dan en relación a su propia actividad, implicando cuestiones técnicas, económicas, medioambientales, sociales, políticas, etc. Toda esa red de relaciones en torno a la cual se va erigiendo el sector de la AF en Bermejo, dio lugar a las iniciativas que dan forma agroecología en esta zona. Una de ellas es la Feria Regional de Intercambio de Semillas, organizada por primera vez en 2010 por el ProHuerta y la Secretaría de Agricultura Familiar, en colaboración con la red de promotores, la ONG, el municipio de Las Palmas y los CPSR. Desde ese año, la Feria se realiza anualmente, convocando a técnicos y productores de la provincia y del noreste argentino, quienes traen sus semillas, plantines y experiencias para intercambiar. El evento es fomentado como un ámbito donde se promueve el "intercambio de saberes" para "mantener las variedades" de semillas criollas en el marco de la construcción de "la soberanía alimentaria". En la formulación de los slogans y en los sentidos transmitidos durante las reuniones organizativas, los técnicos del INTA transmiten su visión sobre este espacio de encuentro: congregar a los pequeños productores de la región cuyo rol es esencial en la construcción de la soberanía alimentaria. Por eso, se esfuerzan en traer productores de otros lugares con mayor experiencia en organizaciones sociales y promueven el intercambio de semillas que no se consigan en la zona para fomentar una mayor biodiversidad, como expresa un técnico de ProHuerta en una entrevista que le hicieron desde una radio de Resistencia ante la realización de una nueva feria de semillas:

"estamos tratando conseguir distintos tipos de semillas para inyectar biodiversidad: por ejemplo, el poroto sable, que se usa mucho en la parte de Misiones para todo lo que es abono verde. Estamos tratando de gestionar para que quede instaurado y distintos tipos de productores empiecen a producir esa semilla. Entonces, nosotros después sabemos qué productor produce y tenemos el contacto para que después se pueda llegar a ofrecer a otros productores que puedan llegar a necesitar." (Registro, octubre 2016).

Como un agente activo en la creación de la realidad social del territorio, el técnico pone en juego su capacidad de movilizar recursos y de promover un determinado comportamiento entre productores: la conservación y reproducción de semillas. Así se genera una dinámica de don y contra-don, donde en contrapartida de la semilla (don de los técnicos) (Cowan Ros, 2013), los productores contraen el compromiso de cuidarla.

Los pequeños productores participan con diferentes objetivos: vender hierbas medicinales y artesanías, mejora la ecuación económica ya que la práctica de conservar las semillas es fundamental pues "hoy, en el mercado, sale mucha plata" (presidente de un CPSR, registro etnográfico del acto de apertura de la Feria de semillas de 2016); conocer otros productores por fuera del Departamento, entre otros. Para que la Feria cumpla su rol, es importante que el intercambio de semillas se realice antes o durante la época de siembra. Augusto y su esposa Camila, productores criollos de unos 40 años, nos comentaron su primera experiencia en una feria de semillas, realizada en el año 2000 en la Sociedad Rural de Quitilipi, a 150 kilómetros de su chacra en Bermejo:

"Augusto: nosotros guardábamos siempre, en paquetes de yerba que mantenía la humedad, todo eso [semillas]. Y llevamos semillas de rúcula, lechuga (...) Y allá [en Quitilipi], nos dieron todas las bolsitas chiquititas para desapartar. Cuando llegamos nosotros ya eran las 9:30, 10. Ya estaban todos los tablones, no había más lugar para nosotros. Nos dijo el Sergio ${ }^{11}$ : 'bueno, miren, caminen nomás ustedes, y si alguna semilla les gusta, hagan intercambio, carguen su bolsita'. Y así hicimos. Pero todo el día, casi, parados, caminando... Y después, llegó las 2:00/2:30, pasaba el colectivo y teníamos que venir (...)

\footnotetext{
${ }^{11}$ Referente del ProHuerta en la década de 1990 y la primera mitad de los 2000.
} 
esa fue nuestra experiencia. Fue bastante rústica, digamos (...) Era como llegar ahí y no saber...uno que Augusto no tenía... Ahora Augusto, habla un montón, más antes, no." (Registro, mayo 2017).

Otros productores nos transmitieron esta misma dinámica de intercambio, indicando la centralidad de la semilla en la producción de alimentos y el rol de estos encuentros que impulsan a seleccionar variedades adaptadas a las condiciones locales, preservando la biodiversidad. Además de contribuir al proceso material de reproducción del sistema agroalimentario local, la participación reiterada en esta experiencia junto a productores de otros territorios, que tienen otras prácticas productivas y sociales, deja huellas subjetivas: Augusto, que no tenía el hábito de hablar, ahora "habla un montón", dice su esposa Camila. Así como Augusto, actualmente uno de los principales referentes de la AF en el departamento Bermejo, otros productores y productoras se fueron movilizando por distintos ámbitos de intercambio, de la mano de técnicos de agencias estatales y de ONGs, volviéndose más experimentados en el manejo de la palabra.

La participación de pequeños productores en los diferentes ámbitos de promoción de la agroecología y de la producción sustentable fue generando una base de experticia para redactar presentaciones a las convocatorias nacionales e internacionales para acceder al financiamiento, gestionar los proyectos y hacer la rendición contable. Asimismo, se consolidaron redes interinstitucionales, integradas por actores heterogéneos (agencias del estado, comunidad científica, organizaciones e instituciones locales, etc.) que contribuyeron a asentar la identidad agroecológica de los pequeños productores involucrados en ellas. Estas iniciativas se articularon con otras dinámicas existentes en el territorio, como la creación de los CPSR.

En Bermejo, uno de los CPSR en conjunto con los técnicos del ProHuerta, puso en pie en 2015 la Feria Franca, un mercado de proximidad que atiende 3 veces por semana en una zona céntrica de dicha localidad. Allí se comercializan productos "agroecológicos", buscando asegurar la viabilidad económica de las unidades en "transición hacia" ese nuevo sistema productivo, tal como nos comentó Augusto, referente de la Feria:

"La Feria Franca se creó (...) para dar la oportunidad de que ellos [productores del CPSR] produzcan y se acerquen al mercado. Porque tenemos una necesidad y una demanda terrible de parte del pueblo, para que traigamos la producción orgánica." (Registro, mayo 2016).

En el trabajo de campo pudimos observar cómo la Feria Franca y el Programa ProHuerta cumplen un rol de acompañamiento en la construcción de estas capacidades a nivel de los actores locales, formando a los "más vergonzosos" en las prácticas de comercialización de sus productos mediante charlas con expertos, encuentros con otros productores ya integrados a otras ferias, organización de actividades de intercambio de semillas, etc. La "vergüenza" evocada por estos productores "en transición a la agroecología" es una experiencia compartida que relacionan con tener que exponer sus mercaderías a un cliente. El pasaje de productor a comerciante es el pasaje de naturaleza a mercancía, y la vergüenza puede ser vista como el impacto de dicho pasaje en el plano de la subjetividad. En ese mismo intercambio, Augusto expuso las condiciones que llevan a los pequeños productores a adoptar este sistema de producción:

"Todos nosotros, pequeños productores, producimos en forma natural y orgánica porque no tenemos acceso al efectivo para comprar todo lo que sea el paquete tecnológico, que ellos le llaman fertilizante, todas esas cosas. Lamentablemente, ahí producimos a lo natural nomás. Y por ahí nosotros no podemos producir en forma artificial digamos, sacar una lechuga linda en tan poco tiempo. Sacamos sí también lechuga, pero tenemos que hacer todo un preparado del suelo con bosta, todo eso lleva." (Registro, mayo 2016). 
Tal como la literatura relevó para otros casos de adopción de la agroecología (Machín Sosa et al., 2010), la condición de "pobre" que alude Augusto, en un contexto donde hay una demanda por alimentos sin agrotóxicos, genera una oportunidad para estos pequeños productores que pueden posicionarse en el mercado de la "producción orgánica". Con estas premisas se formó la Feria donde hoy venden 9 familias de forma regular, y otras 4 que asisten esporádicamente. Hay una clara mayoría de mujeres atendiendo los puestos (7), aunque vayan los hombres de la familia, son ellas las que abordan a los clientes. En la Feria vemos representada toda la diversidad de situaciones descripta más arriba: indígenas y criollos, algunos involucrados en conflictos de tierra y otros que están en situaciones más o menos estables, mujeres y hombres, todos integrados a instituciones o iniciativas para la AF (CPSR, Programa ProHuerta, etc.). También hay quienes cuentan con ganado vacuno para la venta o realizan un trabajo remunerado como peones de estancia. Además, todos reciben algún plan o asignación del estado (AUH, pensión por discapacidad).

La organización de la Feria establece algunas pautas de funcionamiento, como promover la no superposición de productos, acordar entre todos los precios de venta, construir una identidad de la Feria (logo, uniforme para atender, carpa, etc.). Estos acuerdos buscan reducir la competencia entre los integrantes y evitar conflictos, aunque las tensiones que registramos suelen estar vinculadas a estos mismos aspectos que se intentan pautar. En general, la repetición de los productos ofrecidos es recurrente. Por su parte, hay voces que pesan más que otras en las discusiones sobre los precios, sobre todo las de los dirigentes que promueven que la feria tenga precios más elevados que los de las verdulerías. Hay quienes consideran que esto los hace menos competitivos, ya que se reduce la gente que está en condiciones de comprar los productos ofertados. De un modo general, la Feria se configura centralmente como un espacio de organización desde donde se visibiliza al sector, se generan nuevos vínculos con los consumidores y las autoridades locales (logrando, por ejemplo, que en 2018 los festejos por el aniversario del mercado fueran declarados de interés municipal).

También es un ámbito importante de formación en prácticas de manejo agroecológico. Por un lado, en las conversaciones entre las y los feriantes intercambian consejos para la producción, siendo uno de los tópicos recurrentes el calendario lunar en relación a los momentos de siembra y cosecha. También se generan intercambios a nivel de las prácticas productivas (cómo realizar las tareas para que sean más eficaces, o qué productos utilizar para combatir las plagas ${ }^{12}$ ).

Además de la Feria de intercambio de semillas y de la Feria Franca, existe una tercera iniciativa relativa a la agroecología, liderada por una organización socio-política (el Movimiento Social - MS)): la creación de la Tecnicatura de agroecología. Esta iniciativa pone en el centro de la escena al referente político provincial de dicha organización: "el proyecto en sí, surgió del Maestro líder que es Luis González, que tenía en la cabeza el tema del Cuidado del Medio Ambiente". Esta preocupación quedó reflejada en el lema de la Tecnicatura agropecuaria con orientación agroecológica: "Necesitamos de jóvenes

12 Por ejemplo, una mañana en que conversamos con Marta y María, madre (50 años) e hija (28) respectivamente, luego del Mercado discutieron cuál era la mejor forma de realizar la tarea de la carpida (retirar los yuyos): Marta estaba acostumbrada a carpir con herbicidas, pero los compañeros del Mercado le habían dicho a María que eso dañaba las propiedades del suelo, haciendo que luego sea necesario aplicar fertilizantes como la urea. Por lo tanto, María convenció a la madre para que contraten peones que hagan la carpida a mano, arrancando los "yuyos" de raíz, del mismo modo que lo hace Elvira, otra señora del Mercado. 
que conozcan la riqueza de nuestro suelo, ríos y que comprendan de la importancia de su cuidado para el crecimiento de la comunidad." El proyecto, presentado en 2016 a las autoridades provinciales, inició las actividades un año después, con 100 inscriptos. La idea de crear esta tecnicatura se basó, por un lado, en la disponibilidad de los recursos para la producción (tierra, semillas, aves y capacitación proporcionadas por el Programa ProHuerta); por el otro, en las características socioeconómicas locales: "el tema de la desocupación acá [Bermejo] es impresionante y la cultura de trabajo no está implementada" (referente local del MS, entrevista 2017). Estos dos aspectos se articularon en la mirada que el MS tiene sobre lo ambiental, en tanto cuestión de interés general inscripta en el horizonte del Estado. Así lo sintetizó el referente que coordinó la iniciativa a nivel local:

"nosotros lo que queremos es el cuidado [del ambiente]: fijate, basura por todos lados!

Nosotros queremos cambiar esa cultura (...) y empezar a laburar y que se creen más fuentes

de trabajo para toda la gente de Bermejo, pero siempre trabajando, no cobrando [los planes

sociales] de balde, sino trabajando. Esa es más o menos la idea nuestra, la historia de cómo

surge todo esto del tema de la tecnicatura." (Entrevista, mayo 2017).

Vemos en esta iniciativa cómo las tres dimensiones de la agroecología reconocidas en la literatura -práctica productiva, movimiento social y ciencia (Sevilla - Guzmán y Soler Montiel, 2009; Toledo, 2011; Van der Ploeg, 2012) - se conjugan para dar lugar a la tecnicatura.

\section{Conclusiones}

Tanto la Feria de intercambio de semillas, la Feria Franca como la Tecnicatura de Agroecología dan cuenta del incipiente proceso de institucionalización de la agroecología conducido por un sector de los pequeños productores familiares, en articulación con agentes estatales (la agencia de extensión de INTA de Las Palmas, el IDRAF, la Secretaria de Agricultura Familiar de Nación, etc.) y organizaciones sociales de diverso origen (ONG, MS).

En este trabajo pusimos en perspectiva histórica las políticas públicas en Argentina orientadas hacia la AF y el modo en que ellas se conectan con la agroecología, haciendo un foco particular en nuestra zona de estudio: el Departamento Bermejo, provincia de Chaco. En este recorrido mostramos, en primer lugar, cómo las políticas de ajuste estructural de los años 90 dejaron a una buena parte de la población rural como "población sobrante" (Murray Li, 2010), esto es, sin posibilidades de incorporarse (ni siquiera de forma subordinada) al proceso de acumulación del capital, donde nuevas organizaciones laborales y tecnologías desplazaron a trabajadores estacionales y proveedores de materia prima de los complejos agroindustriales. En Bermejo, estas transformaciones fueron decisivas para el cierre del Ingenio Las Palmas del Chaco Austral que hasta ese momento no sólo era garante de las fuentes de empleo e ingresos, sino también del acceso a la tierra. En la nueva etapa dominada por el modelo de agronegocios, las identidades empresariales orientaron la dinámica de desarrollo local hacia sistemas productivos capital intensivo (explotación arrocera, piscicultura) o ganadería extensiva, expandiéndose en ambos casos sobre tierras del Ingenio, donde residían y cultivaban para autoconsumo las familias zafreras. Estas últimas, destinatarias de políticas asistenciales, serán catalogadas durante los años 1990 como "pobres rurales". Objeto de programas nacionales e internacionales de desarrollo rural, se beneficiaron de acompañamiento técnico y capacitaciones, así como de donaciones y subsidios para construir infraestructura local. Aunque estos programas no lograron paliar la situación de pobreza, tuvieron un impacto fundamental 
en las estrategias de reproducción social (Cowan Ros, 2013) al instalar de manera durable una dinámica de trabajo y priorizar temas a nivel local. En estos procesos vimos que se estableció un tipo de dinámica entre las identidades producidas localmente y las políticas públicas destinadas a estos segmentos sociales: los agentes de promoción social se han constituido en mediadores culturales entre la población local y las agencias públicas nacionales $\mathrm{u}$ organismos internacionales, habilitando el acceso a financiamiento $\mathrm{y}$ conocimiento técnico. Sin embargo, en su accionar exceden esa mediación en tanto no sólo conectan esos mundos, sino que construyen y buscan imponer sus sentidos sobre los campos sociales que articulan, intentando modificar las acciones y discursos de las y los productores. Como la participación en proyectos comunitarios es central para la propia reproducción social, buscan corresponder con las expectativas que tienen los técnicos para seguir siendo beneficiarios de futuras prestaciones. Así se establece una "relación de dádiva", donde los extensionistas ponen en juego los recursos institucionales a cambio de determinados comportamientos y compromisos de parte de las y los beneficiarios (Cowan Ros, 2013). En efecto, por un lado, los pequeños productores aprendieron a conformar pequeños grupos por objetivos, en función de presentaciones a proyectos con financiamiento internacional o nacional; por otro lado, comenzaron a interiorizar como propios temas relacionados con la promoción del cuidado del medio ambiente, la conservación de la biodiversidad o la adaptación al cambio climático.

A partir de las acciones desarrolladas en el marco de programas y políticas para la AF, se fueron formando las redes de actores locales en torno a la producción local de alimentos. Sobre la base de estas redes y la organización lograda en torno de la disputa por la tierra, se asentarían las posteriores políticas de transición hacia la agroecología como el enfoque productivo apropiado para los pequeños productores de Bermejo.

Aunque en sus definiciones operativas y conceptuales, la figura de AF incluía distintos tipos de actores (desde productores con cierto grado de capitalización hasta perfiles campesinos), en la práctica las poblaciones beneficiarias fueron las más marginales. En un contexto de predominancia del modelo de agronegocios, el apoyo al sector de la AF adoptó la lógica asistencialista; cuando, a partir de 2004, estas políticas optaron por la agroecología como sistema productivo para la AF e impulsaron la idea de levantar los estándares de producción para tener un excedente destinado a la venta en ferias locales, los destinatarios de dichas políticas pasaron de ser "asistidos" a ser "pequeños productores en transición hacia la agroecología", con funciones sociales y económicas. En la última etapa, en el contexto de los objetivos de desarrollo sustentable, además de garantizar la seguridad alimentaria, estos actores también tendrán el rol de cuidado del medio ambiente.

Así se desplegaron las políticas de AF, impulsando el desarrollo de experiencias concretas de transición a la agroecología y propiciando ámbitos de encuentro entre actores heterogéneos (academia, sector productivo, política pública, etc.). Por su parte, los actores territoriales se apropiaron de estas políticas para desarrollar estrategias propias que llevaron a procesos de institucionalización de la agroecología (Feria de semillas, Feria Franca, Tecnicatura). De este modo, se reposicionaron como un actor a ser reconocido no ya como "pobre rural", sino como "necesarios" en tanto proveedores de alimentos sanos y ecológicos. En este sentido, la agroecología se constituye en el horizonte de sentido que les permite ofrecer sus productos como una mercancía destacada en el mercado local de alimentos, conforme al imperativo moral global de desarrollo sustentable e inclusivo. 


\section{Bibliografía}

Altieri, M. A., y M. K. Anderson (1986) "An ecological basis for the development of alternative agricultural systems for small farmers in the Third World" - American Journal of Alternative Agriculture 1 (30-38)

Altieri, M. A., y V. Toledo. (2010) "La revolución agroecológica de América Latina: Rescatar la naturaleza, asegurar la soberanía alimentaria y empoderar al campesino" - $E l$ Otro Derecho 42 (63-202)

Beccaria, L.; Roxana, M. y V. Esquivel. (2005) "Empleo, salarios y equidad durante la recuperación reciente en la Argentina" - Desarrollo Económico 45 (235-262)

Castilla, M. I. (2017) "De lo global a lo local: Políticas y surgimiento de organizaciones étnicas en Pampa del Indio, Chaco.” - Papeles de trabajo 34 (29 - 44)

Craviotti, C. (2014) "La agricultura familiar en Argentina: Nuevos desarrollos institucionales, viejas tendencias estructurales" en Agricultura familiar en Latinoamérica: Continuidades, transformaciones y controversias - Craviotti, C. (Comp) (175-204) Ciccus: Buenos Aires.

Cowan Ros, C. J. (2013) "Laberintos de la emancipación. Reciprocidad y conflicto entre agentes de promoción social y dirigentes campesinos" - Revista de Antropología Social 22 (287-312)

Ferrau, M. (2003) Las Palmas del Chaco Austral: Un caso de fábrica con villa obrera Universidad Nacional de Formosa - Las Palmas, Chaco.

Foucault, M. (1999) "8. La «gubernamentalidad»”. En Estética, ética y hermenéuticaFocault, M (175-197) Paidós: Barcelona

Fueyo Sánchez, L.D. (2014) "Transformaciones y disputas territoriales en Bermejo, Chaco. El caso el ex ingenio Las Palmas" - XI Congreso Argentino de Antropología Social - Rosario.

Giraldo, O. y P. Rosset. (2016) "La agroecología en una encrucijada: Entre la institucionalidad y los movimientos sociales" - Guaju 2 (14-37)

Gisclard, M., G. Allaire y R. Cittadini. (2015) "Proceso de institucionalización de la agricultura familiar y nuevo referencial para el desarrollo rural en la Argentina" - Mundo Agrario 16 (1-18)

Gordillo, G. (1995) "Después de los ingenios: La mecanización de la zafra saltojujeña y sus efectos sobre los indígenas del Chaco Centro-Occidental" - Desarrollo Económico 35 $(105-126)$.

Gras, C. y V. A. Hernández. (2008) "Modelo productivo y actores sociales en el agro argentino" - Revista mexicana de sociología - 2 - UNAM - CDMX (227-259)

(2016a) "Hegemony, Technological Innovation and

Corporate Identities: 50 Years of Agricultural Revolutions in Argentina" - Journal of Agrarian Change 16(4) (675-683).

(2016b) Radiografía del nuevo agro argentino. Del terrateniente al empresario transnacional - Siglo XXI: Buenos Aires.

Gudynas, E. (2011): "Buen Vivir: Germinando alternativas al desarrollo" - América Latina en movimiento 462 - (1-20)

Hernández, V. A. (2007) "El fenómeno económico y cultural del boom de la soja y el empresariado innovador" - Desarrollo económico 47 (331-365). 
(2009) "Ruralidad globalizada y el paradigma de los agronegocios en las pampas gringas". En La Argentina Rural. De la agricultura familiar a los agronegocios - Gras C. y V.A. Hernández (Comps) (39-64) Biblos: Buenos Aires

(2019) "Postura antropológica en tiempos de tecnociencia y espectáculo" En Malestar en la etnografía, malestar en la antropología - Epele, M. y R. Guber (Comps) (148-170) Ediciones UNSAM: Buenos Aires

Hernández, V. A., Fossa Riglos, F. y E. Muzi. (2013) “Agrociudades Pampeanas: Usos Del Territorio" En El agro como negocio: Producción, Sociedad y Territorios en la Globalización - Gras, C. y Hernández, V.A. (Comps) (123-150) Biblos: Buenos Aires Hernández, V. A., F. Goulet, D. Magda, N. Girard y J. S. Casadinho. (2014) La agroecología en Argentina y en Francia: Miradas cruzadas - INTA Ediciones: Buenos Aires.

Ivancovich, T. (2015) La agroecología como moral del Estado - Facultad de Filosofía y Letras, Universidad de Buenos Aires - Buenos Aires.

Lattuada, M. (2014). "Políticas de desarrollo rural en la Argentina. Conceptos, contexto y transformaciones" - Temas y Debates 27 (13-37)

Lattuada, M. J., Nogueira, M. E., y Urcola, M. (2015) Tres décadas de desarrollo rural en la Argentina: Continuidades y rupturas de intervenciones públicas en contextos cambiantes (1984-2014) - UAI Editorial: Buenos Aires.

MANZANAL, M. (2017) "Desarrollo, territorio y políticas públicas. Una perspectiva desde el desarrollo rural y territorial" - Revista Interdisciplinaria de Estudios Agrarios $46(5-31)$

Marcus, G. E. (2001) "Etnografía en/del sistema mundo. El surgimiento de la etnografía multilocal" - Alteridades 11(22) (111-127).

Meillassoux, C. (1977) Mujeres, graneros y capitales - Siglo XXI: México.

Murmis, M. (1998) "El agro argentino: Algunos problemas para su análisis". En Las agriculturas del MERCOSUR: el papel de los actores sociales - Giarracca, N. y S. Cloquell (Comps) (205-248) Editorial La Colmena: CLACSO: Buenos Aires

Murray LI, T. (2010) "To Make Live or Let Die? Rural Dispossession and the Protection of Surplus Populations" - Antipode 41 (66-93)

Restrepo, E. (2016) Etnografía: alcances, ténicas y éticas - Envión editores: Bogotá.

Rozé, J. (2007) Lucha de clases en el Chaco contemporáneo (1ra ed.). - Librería de la Paz: Resistencia, Chaco.

Sabourin, E., M. M. Patrouilleau, J. F. Le Coq, L. Vazquez y P. NIEDERLE. (2017) Políticas públicas a favor de la agroecología em América Latina y El Caribe. Evangraf / Criação Humana, Red PP-AL: FAO : Porto Alegre.

Sarandón, S. J. y C. C. Flores. (2014): Agroecología - Editorial de la Universidad Nacional de La Plata: La Plata.

Schaller, E. (1986): La colonización en el Territorio Nacional del Chaco en el período 1869-1921. Instituto de Investigaciones Geohistóricas-Conicet-Fundanord: Resistencia, Chaco.

Schiavoni, G. (2010). "Describir y prescribir: La tipificación de la agricultura familiar en la Argentina" en Las agriculturas familiares del Mercosur: Trayectorias, amenazas y desafíos - Manzanal, M. y G. Neiman (Eds.) (43-60) Ciccus: Buenos Aires Señorans, D. (2017). “«Con el corazón, con la mente y con las manos»: Emociones y valores en las prácticas políticas colectivas de militantes y trabajadores de la economía popular". Papeles de Trabajo 34 (76-91) 
Sevilla - Guzmán, E. y M. Soler. (2009): "Del desarrollo rural a la agroecología. Hacia un cambio de paradigma" - Documentación social 155 (25-41)

Shore, C. (2010): "La antropología y el estudio de la política pública: Reflexiones sobre la "formulación" de las políticas" - Antípoda. Revista de Antropología y Arqueología 10 (21-49)

Souza Casadinho, J. (2014): "La agroecología: Bases científicas, historia local y estrategias productivas en la construcción de un espacio de desarrollo integral, ético y humano". En La agroecología en Argentina y en Francia: Miradas cruzadas Hernández, V.A., F. Goulet, D. Magda, N. Girard y J. Souza Casadinho (EDs) (13-29) INTA Ediciones: Buenos Aires

Soverna, S. (2016): "Políticas de desarrollo rural en Argentina". En Problemas actuales del agro argentino - Tsakoumagkos, P. (Coord) (435-462) Editorial de la Facultad de Filosofía y Letras de la Universidad de Buenos Aires: Ciudad Autónoma de Buenos Aires Soverna, S., P. Tsakoumagkos y R. Paz (2008): Revisando la definición de agricultura familiar - Secretaría Agricultura, Ganadería, Pesca y Alimentos - Buenos Aires.

Tilman, D. (1999): "Global environmental impacts of agricultural expansion: The need for sustainable and efficient practices" - Proceedings of the National Academy of Sciences $96(5995-6000)$

Toledo, V. (2011): "La agroecología en Latinoamérica: Tres revoluciones, una misma transformación" - Agroecología 6 (37-46)

Van Der Ploeg, J. D. (2012): Nuevos campesinos. Campesinos e imperios alimentarios Icaria: Barcelona.

Vía Campesina. (2015): Declaración del Foro Internacional sobre Agroecología Nyéléni, Mali.

\section{Documentos en línea:}

https://www.indec.gob.ar/textos_glosario.asp?id=14

http://prohuerta.inta.gob.ar/acerca-de/

https://www.ucar.gob.ar/index.php/prodernea

https://viacampesina.org/es/declaracion-del-foro-internacional-de-agroecologia/ 